\title{
PORTAL \\ DE \\ LIBRAS
}

PORTAL LIBRAS

\author{
LIBRAS PORTAL
}

Renata Krusser*
Instituto Federal de Santa Catarina $\mid$ campus Palhoça Bilíngue

Daniela Saito** $^{* *}$

Instituto Federal de Santa Catarina | campus Palhoça Bilíngue

Ronice Müller de Quadros***

Universidade Federal de Santa Catarina

RESUMO: O Portal de Libras é uma interface que centraliza uma série de materiais e ferramentas disponíveis que tenham relação com a língua brasileira de sinais (Libras) e que possam ser usadas para fins de pesquisa e para fins educacionais. O Portal de Libras foi desenvolvido para compreender ferramentas que fomentem a constituição de uma rede de formação e/ou comunidade de prática, viabilizando o compartilhamento de conhecimentos e a interação em Libras e em Português. Ela foi desenvolvida levando em conta aspectos relacionados à acessibilidade e à usabilidade web, sobretudo no que tange aos vídeos em Libras, uma vez que estes deverão permitir a fácil utilização do site, tanto em relação ao acesso aos menus e aos hiperlinks, quanto à utilização das ferramentas de comunicação disponibilizadas na comunidade de prática. Além disso, o sistema de gerenciamento de conteúdo do Portal foi customizado de modo a suportar a disponibilização dos vídeos sem a necessidade de implementação via código. O layout apresenta um design atraente e explora recursos visuais compatível com os usuários surdos. Foram desenvolvidas ferramentas que favoreçam a acessibilidade, indexação de informações e upload de vídeos, constituindo-se esta etapa numa possibilidade de pesquisas e desenvolvimento de produtos que poderão ser revertidos a toda comunidade surda e ouvinte. Ademais, a rede/comunidade dispõe de repositórios para compartilhamento de materiais, tais como imagens, arquivos, fotos, ferramentas de apoio à decisão, ferramentas visuais para atividades colaborativas. O desenvolvimento envolveu várias pesquisas que serão descritas neste artigo.

PALAVRAS-CHAVES: Design. Interface bilíngue. Acessibilidade.

\footnotetext{
* Renata Krusser é designer e professora da área de design e multimídia no Instituto Federal de Santa Catarina (IFSC) câmpusPalhoçabilíngue.E-mail:renata.krusser@ifsc.edu.br.

** Daniela Saito é professora e pesquisadora de multimídia e acessibilidade no Instituto Federal de Santa Catarina (IFSC) câmpusPalhoçabilíngue.E-mail:daniela.saito@ifsc.edu.br.

*** Ronice Müller de Quadros é professora e pesquisadora da Universidade Federal de Santa Catarina, no Departamentode Libras e pesquisadoradoCNPQ E-mail:ronice.quadros@ufsc.br
} 
RESUMEN: El Portal de Libras es una interfaz que centraliza una serie de materiales y herramientas disponibles que tienen relación con la lengua de señas brasileña (Libras) y que pueden ser utilizados con fines investigativos y educativos. El Portal de Libras se desarrolló para comprender las herramientas que fomentan la formación de una red de capacitación y/o comunidad de práctica, permitiendo el intercambio de conocimientos y la interacción en Libras y en portugués. Se desarrolló teniendo en cuenta aspectos relacionados con la accesibilidad y utilidad en la web, especialmente en lo que respecta a los videos en Libras, teniendo en cuenta que estos deben permitir un fácil uso del sitio web, tanto en lo relacionado con el acceso a menús e hipervínculos, como con el uso de herramientas de comunicación disponibles en la comunidad de práctica. Además, el sistema de gestión de contenido del Portal se personalizó para admitir la disponibilidad de videos sin la necesidad de implementación de códigos. El formato presenta un diseño atractivo y aprovecha recursos visuales compatibles con los usuarios sordos. Se desarrollaron herramientas que favorecen el acceso, la indexación de información y la carga de videos, constituyéndose esta etapa en una posibilidad de investigación y desarrollo de productos que pueden ser compartidos a toda la comunidad de personas sordas y oyentes. Además, la red/comunidad tiene repositorios para compartir materiales, como imágenes, archivos, fotos, herramientas de apoyo a la toma de decisiones, herramientas visuales para actividades colaborativas. El desarrollo involucró varias investigaciones que se describirán en este artículo.

PALABRAS CLAVE: Diseño. Interfaz bilingüe. Accesibilidad.

ABSTRACT: The Libras Portal is an interface that makes available in one place a series of materials and tools related to Brazilian Sign Language (Libras) and it can be used either for the purpose of research and educational goals. The Libras Portal was developed to encode tools that support the constitution of a network for education and/or community of practice, making the sharing of knowledge and the interaction in Libras and Portuguese possible. It was developed considering aspects related to web accessibility and usability, especially with respect to videos in Libras, because these will facilitate the use because of the menu access and hyperlinks, regarding to the tools available related to communication considering the target community of practice. The layout presents an interesting design and it explores the visual resources compatible with deaf users. It developed tools in favour of accessibility, information indexicalization and upload of videos as a set of product research and development that will make possible the use by deaf and hearing communities. Moreless, the network and community offer repositories for material sharing, such as images, files, pictures, support tools to help the decisions, visual tools for collaborative activities. The development included various researches that will be described in this paper.

KEYWORDS: Design. Bilingual interface. Accessibility.

\section{INTRODUÇÃO}

O desenvolvimento do Portal de Libras (LIBRAS, 2020) incluiu os pesquisadores de todas as instituições envolvidas no projeto, em especial, a equipe especialista em tecnologia, comunicação multimídia e design da Universidade Federal de Santa Catarina (UFSC) e do Instituto Federal de Santa Catarina (IFSC). O Instituto Federal de Santa Catarina conta com os cursos técnico em Comunicação Visual e graduação Tecnologia em Produção Multimídia que incluem pesquisadores das áreas de design, computação gráfica e tradução de vídeos aplicados para a educação bilíngue para surdos. A Universidade Federal de Santa Catarina conta com pesquisadores da área da tecnologia voltada para a acessibilidade web e educação bilíngue para surdos. Essa composição viabilizou a concepção das interfaces digitais multilíngues, didáticas e acessíveis do Portal de Libras.

A metodologia adotada para as questões técnicas foi composta pelas seguintes etapas:

1) Levantamento do referencial teórico considerando temas relacionados a acessibilidade web, desenvolvimento de interfaces bilíngues (língua de sinais e língua oral na modalidade escrita), usabilidade e recuperação de informações. O levantamento foi realizado em bases indexadas de caráter multidisciplinar, de modo a abranger as diversas temáticas relacionadas ao desenvolvimento de interfaces tecnológicas acessíveis.

a) Em relação à acessibilidade:

i) Promover coexistência harmônica entre a língua de sinais e a língua oral em sua modalidade escrita.

Os autores identificados na busca (FOTINEA; EFTHIMIOU, 2008; LI; XU, 2009; NASR, 2010; 
TRINDADE; GUIMARÃES; GARCÍA, 2013) afirmam que esta perspectiva, além de ampliar a acessibilidade, estimula a aprendizagem da língua oral escrita além de estimular a interação entre surdos e ouvintes.

ii) Autores como Li e Xu (2009), Nasr (2010), e Trindade, Guimarães e García (2013) salientam a importância de se considerar as particularidades do modo de comunicação dos surdos na seleção das ferramentas tecnológicas a serem disponibilizadas. Esta consideração tem em vista impactar a motivação dos usuários surdos, fomentar a participação ativa na comunidade, bem como a formação do senso de identidade daqueles que fizerem parte da comunidade de prática. Para tanto, sugere-se a disponibilização de ferramentas de interação e comunicação (sejam elas síncronas ou assíncronas), ferramentas de cooperação e ferramentas de colaboração que tenham um caráter visual. Entre os exemplos de ferramentas podem ser elencados: fóruns de discussão que contemplem o uso de imagens e de vídeos em língua de sinais; ferramentas colaborativas de geração de mapas mentais e mapas conceituais; funcionalidades cooperativas para a validação de conteúdo (exemplos: curtir e não curtir, rankeamento, entre outros).

b) Para a usabilidade de interface:

i) A navegabilidade do sistema deve ser projetada incorporando a língua de sinais e a existência de feedbacks ao usuário (FOTINEA; EFTHIMIOU, 2008; LI; XU, 2009). De acordo com Flor (2016), o uso de traduções em língua de sinais para auxiliar a navegação diminui as ambiguidades e equívocos com palavras distratoras em português.

ii) Recomenda-se que os ícones tenham forma semelhante ao objeto que representam e, quando existirem ícones convencionalizados pelo uso, optar pela convenção, visto que são mais familiares e funcionais (FLOR, 2016; HICKS, 2011).

iii) Para melhor desempenho de leitura e uso das funções disponibilizadas, Flor (2016) aponta que os vídeos explicativos devem estar na mesma página e próximos aos conteúdos correspondentes. Em complemento, aponta a importância de recursos de controle da velocidade de sinalização nos vídeos, tal como será posteriormente explanado neste documento.

2)

Definição dos requisitos do Portal de Libras que contemplou as seguintes sessões:

a) Módulo Materiais: publicações de materiais literários (poesias, contos, narrativas, fábulas, lendas e entrevistas), materiais acadêmicos (livros, teses, dissertações, artigos, revistas e exemplos de Libras) e materiais didáticos (coleções, vídeos, imagens, atividades, textos, recursos interativos, aulas e outros), incluindo e-books, $v$-books, textos em Libras e em português, relacionados com os surdos em diferentes áreas do conhecimento.
i) Acessar materiais
ii) Favoritar materiais
iii) Baixar materiais
iv) Publicar novos materiais

b) Módulo de Cursos (cursos oferecidos no país relacionados com a Libras)
i) Cursos de Libras
ii) Cursos técnicos
iii) Cursos de graduação
iv) Cursos de pós-graduação
v) Outros cursos para surdos
vi) Cadastrar cursos

c) Módulo de Língua (diferentes materiais específicos sobre a Libras)

i) Gramática da Libras: 
Gramática da Libras, em Libras e com áudio em português

Cadastro de outros estudos gramaticais da Libras

ii) Antologias da Libras:

Antologia Literária em Libras

Publicação de outras antologias

iii) Ensino de Libras como L2:

Quadro de referência para o ensino de Libras como L2

Publicação de exemplos de aulas de Libras

iv) Corpus da Libras

v) Signbank da Libras

d) Módulo de Pesquisas

i) Cadastro de pesquisas em desenvolvimento

ii) Estatísticas do Portal de Libras

e) Módulo de avaliação (os materiais publicados no Portal de Libras podem ser avaliados pelos usuários)

f) Módulo Perfil do Usuário (os usuários podem criar um perfil e salvar suas preferências e materiais no seu perfil)

3) Seleção da plataforma para desenvolvimento, considerando os requisitos determinados para o Portal de Libras;

4) Levantamento de ferramentas que atendem à filosofia open source que possam ser agregadas à plataforma;

5) Desenvolvimento dos projetos de design para as diferentes interfaces;

6) Desenvolvimento das atividades de programação do Portal de Libras primando pela filosofia open source;

7) Testes de usabilidade;

8) Disponibilização da plataforma e suas ferramentas para as comunidades surda e ouvinte.

O Portal de Libras envolveu pesquisas na área de design para o desenvolvimento de um projeto de identidade visual que valorizasse a cultura surda e as formas de orientação visual dos surdos. Além de considerar as diretrizes de acessibilidade web, são importantes as recomendações de estudos específicos que analisaram o uso de ambientes web pelos surdos como os de Flor (2016) e Fajardo, Parra e Cañas (2010). Tais estudos destacam a importância do uso da língua de sinais e o uso de recursos visuais contextualizados.

Um ambiente digital, com suas cores, estilo gráfico, imagens e composição transmite uma ideia sobre o conteúdo e pode instigar o interesse pelo tema abordado, pode favorecer que o usuário se identifique com a proposta, participe das interações, e contribua para o desenvolvimento dos conteúdos. Conforme Ambrose e Harris (2011), a tipografia é um dos recursos gráficos que mais influencia o caráter e a qualidade emocional do produto. "Ela pode produzir um efeito neutro ou despertar paixões, simbolizar movimentos artísticos, políticos ou filosóficos, ou ainda expressar a personalidade de um indivíduo ou organização (AMBROSE; HARRIS, 2011, p.6)".

Elementos como espaçamentos, estrutura, pontuação, tipo, estilo e layout desempenham uma função muito importante na articulação dos sentidos (LUPTON; MILLER, 2011). Assim também o design dos textos apresentados em vídeos por intérpretes de língua de sinais que utiliza diferentes elementos do design, mas igualmente importantes para a leitura, navegação e para a qualidade emocional do projeto. A presença de um intérprete é muito marcante e pode atrair a atenção ou despertar antipatia, aproximar ou afastar o usuário. Os estudos sobre recursos videográficos articulados com a interpretação em Libras, sobre o projeto da relação entre as janelas de interpretação com as demais imagens, textos escritos, animações, gráficos ou infográficos e para o enquadramento, cores e estilo visual adotado pelo intérprete reúnem recomendações importantes para o trabalho (CASTRO, 2010; SILVA, 2013; WOLL et. al., 1999).

O design que tem como foco a experiência do usuário deve ser planejado considerando os diferentes aspectos dessa experiência, ou seja, visando que o usuário alcance seus objetivos com eficiência, mas também considerando a qualidade da experiência, em 
seus aspectos perceptivos e emocionais. Para isso é preciso reconhecer que as expectativas, desejos, capacidades e objetivos de cada usuário são diferentes, assim como os contextos de uso. Para projetar a experiência do usuário (User Experience Design ou UX Design) a equipe de projetistas deve contar com a participação dos prováveis usuários ao longo do processo e elaborar protótipos para a realização de testes de usabilidade que conduzam as decisões projetuais (KALBACH, 2009; PREECE; ROGERS; SHARP, 2010; GRANT, 2019).

A partir desses estudos e visando a atender as expectativas dos usuários no acesso aos materiais, manter o padrão gráfico e facilitar a publicação dos diferentes tipos de materiais no portal, foram elaboradas orientações, a partir de recursos visuais e verbais (nas duas modalidades linguísticas), e incluídos recursos para a adaptação automática de formatos, tamanhos e configurações.

O design compreendeu também a organização dos conteúdos em uma interface gráfica que permita a navegação utilizando imagens, Libras e textos escritos. Além do design visual, o projeto com foco na experiência do usuário inclui o projeto da arquitetura de informações e o design de interação. A complexidade das informações reunidas no ambiente bilíngue e a necessidade de oferecer uma navegação que valorize uma orientação pelo visual e pela língua de sinais colocam desafios importantes para os projetistas. Vários pesquisadores estavam produzindo e reunindo materiais em Libras e sobre a Libras e catalogando esses materiais. Tais estudos incluem o Corpus de Libras, gramática da Libras, literatura em Libras, materiais didáticos e acadêmicos, banco de sinais e glossários, referências para o ensino de Libras, exemplos de aulas, grupos e projetos de pesquisas.

Conforme Rosenfeld, Morville e Arango (2015), a arquitetura da informação é o projeto de ambientes de informações localizáveis e compreensíveis. A arquitetura da informação envolve a organização dos dados em categorias, a organização visual dessas categorias, a definição dos caminhos para se navegar entre esses grupos de informações e os sistemas de buscas para localizar conteúdo específico. Inclui também a rotulação, ou seja, a definição dos nomes, e sinais em Libras, e os ícones representativos dessas categorias.

A organização dos materiais resultou num layout que priorizou a clareza, utilizando uma distribuição das informações com pouca profundidade, ou seja, com poucos cliques se pode acessar qualquer conteúdo do portal de Libras.

As orientações para a navegação incluem o uso da língua de sinais e ícones. Na apresentação dos materiais buscou-se explorar os recursos visuais permitindo que se usem filtros para localizar informações de forma mais eficiente e a escolha por visualizar os materiais por capa e título, ordenados pelos mais recentes, ou pela foto e nome dos autores, ordenados por ordem alfabética (Figura 1). 

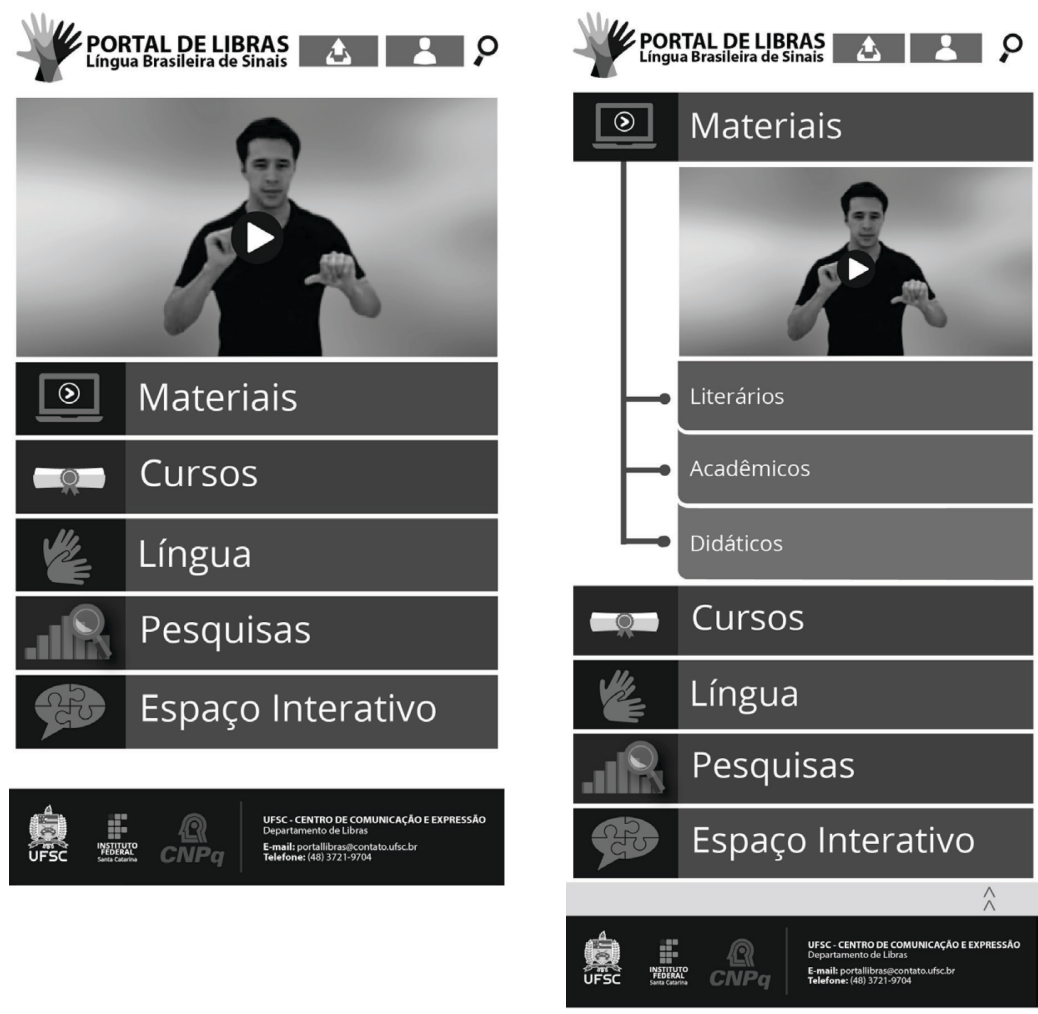

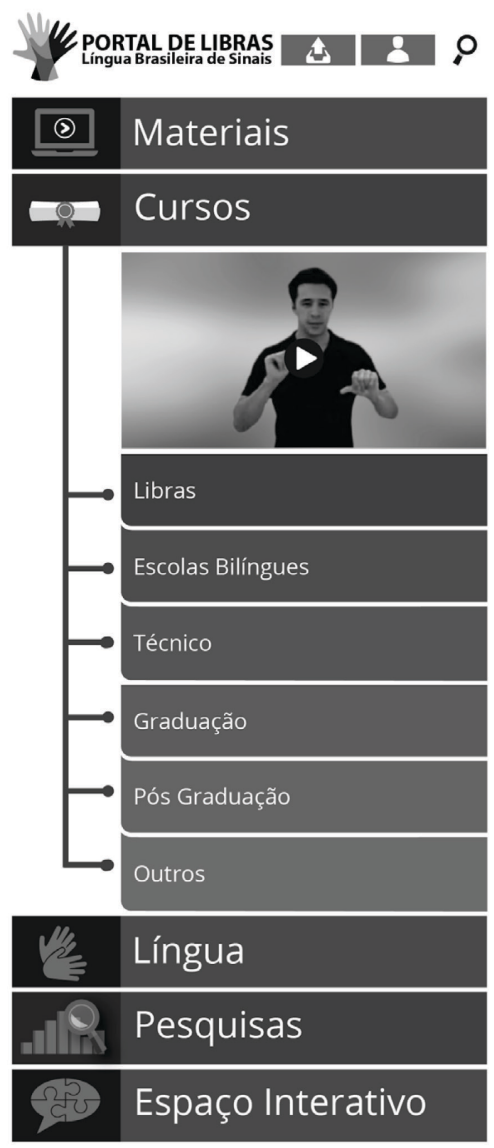

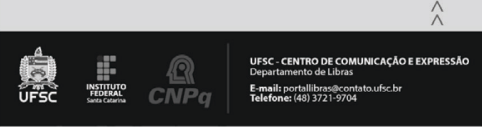



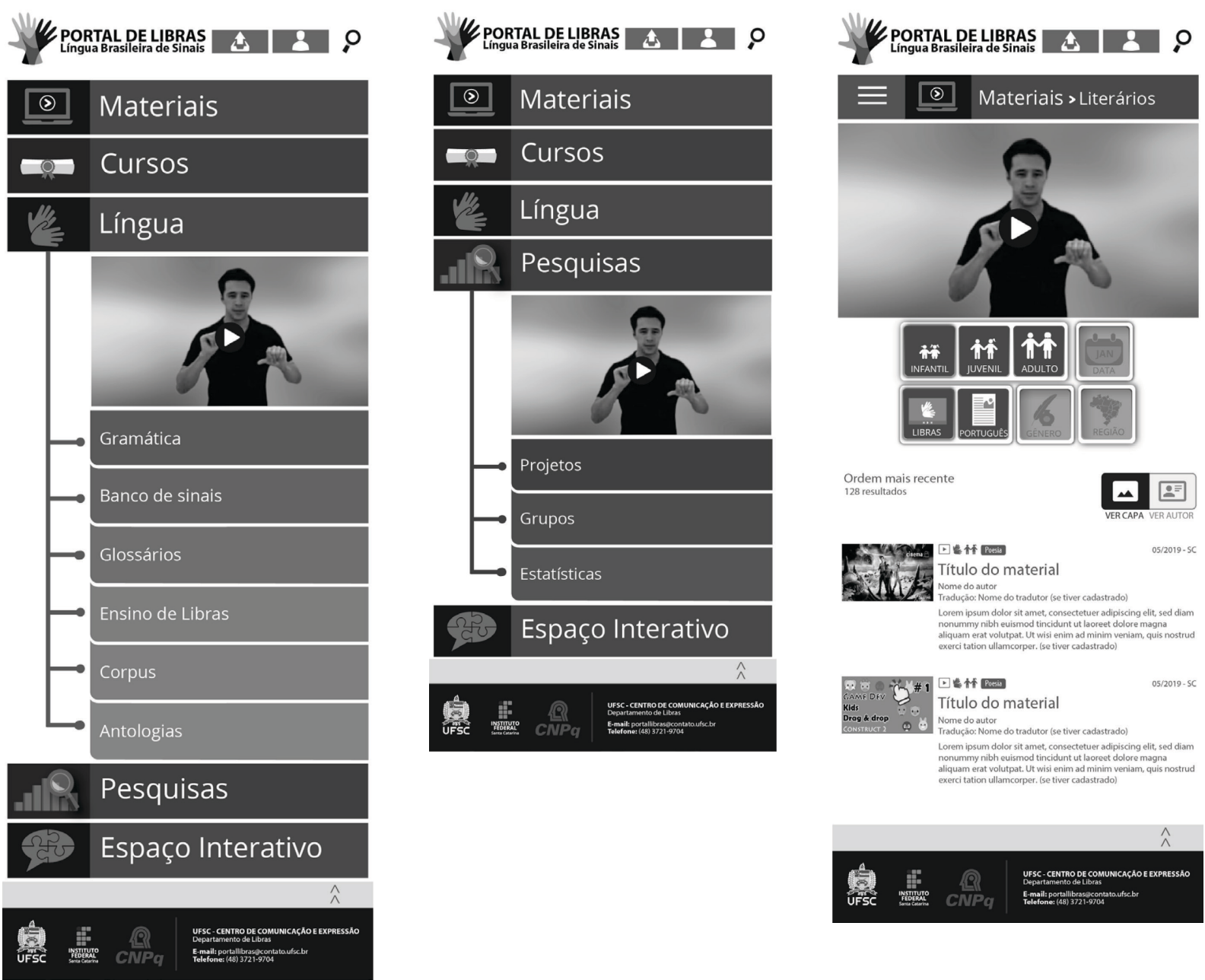

Figura 1: Layout de páginas do portal de Libras: home, menus e Materiais literários (com filtros de infantil, juvenil ou adulto, data, região, gênero literário e língua, Libras ou português) e visualização da lista de materiais por título e capa.

Fonte: LIBRAS (2020)

A definição dos rótulos contou com reuniões entre pesquisadores e estudantes que estavam desenvolvendo as pesquisas na área de Língua de sinais e educação bilíngue, incluindo surdos e ouvintes, que também são prováveis usuários do portal. As discussões, por vezes longas, com decisões que pareciam definitivas e que se transformavam ao longo do desenvolvimento do projeto gerando novas discussões sobre a relação entre o texto em língua de sinais, texto em português escrito e o desenho dos ícones -, evidenciaram a importância da precisão terminológica e a exigência de objetividade e clareza.

Por exemplo, a primeira palavra indicada para representar o conjunto de literatura, produção acadêmica e materiais didáticos foi "biblioteca", e a representação da biblioteca seria a imagem de um livro. Mas a produção em Libras não possui relação com livros impressos e a biblioteca não é um espaço representativo do conhecimento produzido em Libras. Mesmo as bibliotecas digitais e aquelas que incluem textos em vídeos na língua de sinais, geralmente não oferecem ambientes amigáveis para os surdos. Os participantes relataram que enfrentam dificuldades para localizar materiais nos sistemas mais comuns de bibliotecas, como o Pergamum e Sophia. A referência a bibliotecas não é simpática aos usuários surdos e o ícone de um livro não é facilmente associado a vídeos digitais em Libras.

Os textos explicativos dos menus e o desenho dos ícones também precisam de muita objetividade. Fajardo, Parra e Cañas (2010) indicam que o uso de ícones para orientar a navegação na web pelos surdos é eficiente quando representam conceitos comuns e familiares, mas não são adequados quando os conceitos são desconhecidos e abstratos. Nesses casos, o uso da língua de sinais é 
fundamental e precisa estabelecer uma relação muito íntima com as imagens associadas. Por sua vez, o sistema de buscas, recurso que é simples e eficiente em línguas escritas, também demandou pesquisas e busca de soluções tecnológicas.

Os sistemas digitais atuais permitem que se use a palavra escrita para acessar dicionários ou glossários de forma muito ágil, se façam buscas para localizar uma informação em um texto, site ou mesmo na web, e oferecem tradução automática para qualquer língua escrita. Essas facilidades, no entanto, não estão disponíveis para os usuários de línguas de sinais.

Não existem ainda sistemas eficientes e amplamente adotados pelos surdos para buscas a partir de um sinal em Libras visando a localizar uma informação na web e mesmo para localizar um sinal em um glossário ou dicionário. Os glossários e dicionários, na maioria das vezes, oferecem apenas a tradução da língua escrita para a língua de sinais e os poucos que oferecem a opção de buscar pelo sinal exigem selecionar vários parâmetros da língua visual como a configuração de mãos, posição do sinal, direção do movimento. Mesmo com esses filtros, os sinais possíveis são geralmente mostrados por uma imagem, não por um vídeo e organizados por ordem alfabética. Isso dificulta a localização do sinal a ser traduzido.

Os tradutores automáticos funcionam bem na tradução de textos escritos ou orais para a língua de sinais. No Brasil, alguns exemplos bem populares são o VLibras, o ProDeaf e o HandTalk. Mas a tradução da língua de sinais é mais difícil. No mundo inteiro, estão sendo feitos esforços para avançar pesquisas computacionais de reconhecimento automático de sinais, mas esbarram em problemas como um contraste fraco entre a cor das mãos e do rosto na sinalização. A cor da pele também pode não ter um contraste adequado com a cor de fundo ou com a roupa do intérprete. Os movimentos com profundidade, aqueles que não são feitos na frente do intérprete, mas vão de trás para a frente, por exemplo, também dificultam o mapeamento para sistemas de identificação dos sinais.

Nesse sentido, o projeto incluiu o redesign da interface do Signbank da Libras visando facilitar a busca a partir de sinais em Libras. O desenvolvimento de um sistema de localização rápida da configuração de mãos em um slider ${ }^{1}$ deslizante e uma organização gestual dos sinais que utilizam essa configuração foi possível porque a catalogação dos sinais foi feita em um banco de dados com muitos detalhes sobre cada sinal. Foram catalogados o número de mãos usadas para fazer o sinal (uma mão, duas mãos simétricas, duas mãos diferentes), configuração de mãos, localização da articulação do sinal, registro sobre a existência de mudança de orientação, movimento alternado, movimento repetido, movimento direcional, orientação relativa de movimento e localização, forma do movimento e tipo de contato entre as mãos.

Para que o trabalho de design pudesse explorar os recursos de enquadramento, cores e recortes foi necessário filmar e editar novamente todos os sinais e configurações de mãos. São os detalhes na apresentação das imagens que facilitam a identificação visual.

A integração do Signbank permitiu também que fosse desenvolvido um sistema de pesquisa no portal com busca pelo sinal em Libras ou pela palavra escrita. A integração dos textos em Libras, possibilitando acessar os itens do banco de sinais através de links nos vídeos é possível, mas o trabalho exige inserir cada link ao longo dos vídeos e melhorias nesse sistema ainda requer aprofundamento nos estudos de usabilidade e desenvolvimento de recursos computacionais.

Outra proposta do design foi de planejar o design de interação para fomentar a criação de comunidades de prática e facilitar a interação entre surdos e ouvintes. Conforme Preece, Rogers e Sharp (2010), design de interação é o projeto de sistemas para apoiar a comunicação e interação entre as pessoas. Além do desenvolvimento de um espaço interativo, com opções de uso do português escrito e da língua de sinais, o portal de Libras permite que os usuários avaliem os materiais, façam denúncias de conteúdos inadequados e colaborem com o desenvolvimento do portal publicando suas produções literárias, de materiais didáticos, exemplos de aulas, glossários e pesquisas. Existem muitos estudos que resultaram em normas e diretrizes de acessibilidade. No entanto, essas recomendações gerais não são suficientes para promover uma interação intuitiva dos usuários surdos e tem

\footnotetext{
${ }^{1}$ Recurso objetiva aprimorar a experiência do usuário por meio uma estratégia de visualização clara e objetiva de um conjunto de imagens com o auxílio de recursos de interação e de animação.
} 
demandado estudos mais específicos como os de Fajardo, Vigo e Salmerón (2009), Flor (2016) e Li e Xu (2009).

Para facilitar a interação entre os usuários e fomentar o desenvolvimento de comunidades de prática, o espaço interativo oferece orientações visuais e bilíngues e um sistema de buscas para localizar os temas abordados.

Ainda foi realizado o desenvolvimento do design visual/editorial para a Gramática da Libras e o Quadro de Referência para o ensino da Libras. O projeto gráfico para a apresentação do material coletado, organizando as formas de acesso, subsidiou a elaboração de uma gramática da Libras e de um espaço para publicação de diferentes pesquisas sobre os aspectos gramaticais da língua. Também foi desenvolvido o design para o Quadro de referência para o ensino de Libras com espaço para publicação de aulas de exemplo.

O Portal incorporou um banco de dados para armazenar os materiais em Libras, em especial os conteúdos da Antologia Literária e do Corpus de Libras, os quais estarão disponíveis para consultas, pesquisas e uso pelos pesquisadores colaboradores, professores, tradutores, intérpretes de Libras e Língua Portuguesa, assim como demais interessados para fins educacionais. Além disso, o portal conta com espaços desenvolvidos especificamente para fomentar o desenvolvimento da Gramática da Libras e de um Quadro de Referência para o ensino de Libras como segunda língua integrando o banco de dados para ser usado nos espaços educacionais. Ademais, esse banco comporta dados criados a partir do compartilhamento de informações (texto, imagens, vídeos, etc.) realizado na Comunidade de Prática de formação e/ou Rede de formação. A criação de um ambiente de colaboração mediado pela tecnologia vai ao encontro da definição de Davidson (2008) sobre uma geração de ferramentas que é denominada Humanities 2.0: "Humanities 2.0 is distinguished from monumental, first-generation, data-based projects not just by its interactivity but also by openness about participation grounded in a different set of theoretical premises, which decenter knowledge and authority" (DAVIDSON, 2008, p. 711-12)

Considerando que o Portal de Libras e a Comunidade de Prática e/ou Rede de formação favorece a interação em Libras e Português, foram desenvolvidas, customizadas e/ou integradas as seguintes ferramentas:

1) Recursos para busca visual considerando as especificidades da Libras.

2) Ferramentas de interação assíncrona.

3) Ferramentas de colaboração.

4) Sistema de pesquisa por sinais em Libras.

As ferramentas desenvolvidas foram concebidas para serem de fácil uso, sem necessidade de conhecimentos de programação, em diferentes equipamentos; aquelas que forem modularizáveis estarão disponíveis no Portal para download em consonância com a filosofia open source. Esta definição objetivou a disseminação dos conhecimentos desenvolvidos, bem como o estímulo à livrecontribuição da comunidade de usuários para o aprimoramento das ferramentas e tecnologias desenvolvidas.

Em síntese, o Portal de Libras compreendeu os seguintes pontos:

1) O desenvolvimento do Portal de Libras com a possibilidade dos usuários realizarem a gestão de sua aprendizagem, a partir de ferramentas construídas para este fim (exemplo: progresso de leitura, gestão de materiais acessados, favoritos, indicação conteúdos relacionados, colaboração entre os usuários, etc.).

2) A organização e geração de uma base multimídia para o banco de sinais na plataforma internacional de signbanks.

3) A indicação de ferramentas para apoio à realização do projeto e divulgação de materiais em Libras, que estejam em consonância com a filosofia digital humanities, em especial humanities 2.0.

4) A geração de uma base de dados multimídia de objetos de aprendizagem.

5) O desenvolvimento de ferramentas de gestão da plataforma com funcionalidades de desenvolvimento de materiais, gestão de conteúdos e usuários, conteúdos mais acessados, ferramentas de busca semântica e relacional, etc.

6) A integração das informações do portal e das bases de dados utilizadas e geradas. 
O Portal de Libras também está disponibilizando em Libras um amplo acervo de materiais já existentes e de acesso aberto, consolidando este espaço como meio para a rede de formação dos profissionais e alunos da área. Também possibilita o gerenciamento dos recursos educacionais voltados a comunidade surda e aos profissionais que atuam nos cursos de Libras. Destaca-se que estas tecnologias e recursos educacionais viabilizam e potencializam as orientações em Libras, tendo sua eficácia comprovada em experiências anteriores.

O portal também inclui o Corpus de Libras no Inventário Nacional de Libras, no sentido de documentar a Libras de forma representativa no país. Trata-se da metodologia desenvolvida no projeto piloto em Santa Catarina, que foi replicada nos estados de Alagoas, Ceará e Tocantins, que, ao pesquisarem sobre o Corpus de Libras, estão coletando os dados locais no seu estado.

\section{AÇÕES DE EDUCAÇÃO E DIFUSÃO DO CONHECIMENTO}

No âmbito do Portal de Libras, foi prevista a criação de um ambiente público e de acesso livre, que contemplasse materiais em diferentes formatos sobre as questões contemporâneas relacionadas à Libras, com o objetivo de democratizar o acesso às informações e às formações na área. Essa necessidade de livre acesso ao conhecimento produzido vem em sintonia com o debate nacional atual na área, influenciado pelas experiências e políticas internacionais. Há que se considerar que as tecnologias trazem novas formas de aprendizagem, denominada de aprendizagem ubíqua, possíveis devido às vantagens que as redes apresentam em termos de flexibilidade, velocidade, adaptabilidade e de acesso aberto à informação. Caracteriza-se pelo conjunto de processos de aprendizagem abertos, espontâneos, assistemáticos e mesmo caóticos, atualizados ao sabor das circunstâncias e de curiosidades contingentes (SANTAELLA, 2010). Segundo Santaella (2010), esses processos de aprendizagem acontecem com a possibilidade de compartilhamento de diversos espaços-tempos simultaneamente, ao que a autora chamou de ubiquidade. A proposta é, portanto, fazer do Portal de Libras um espaço que permita aos usuários desenvolver essa habilidade de comunicação a qualquer tempo e hora, por meio de diferentes dispositivos móveis. Assim, a ubiquidade está associada à mobilidade favorecendo práticas pedagógicas por meio do acesso às tecnologias, estabelecendo uma nova relação entre espaço e tempo.

A criação do Portal de Libras objetivou responder a uma necessidade premente de acesso à informação qualificada por parte dos profissionais da Educação e da comunidade em geral, e de subsidiar processos formativos de profissionais que atuam com surdos, na perspectiva da difusão do conhecimento nesta temática. A Educação de Surdos avançou celeremente na última década, incorporando uma série de pesquisas sobre esses sujeitos que podem favorecer a suas aprendizagens. No entanto, essas informações ainda são restritas a um pequeno número de profissionais. Portanto, a sua organização de acordo com o público-alvo, divulgação e socialização são de suma importância, agregado ao fato que o Portal destina áreas de colaboração, permitindo que seus usuários também publiquem informações relevantes sobre o tema, garantindo uma permanente atualização e troca de informações e possibilitando a diversificação e articulação da rede de serviços públicos para proteção e cuidado da comunidade surda, tal como previsto nas políticas/planos federais, estaduais e municipais.

Todos os materiais elaborados estão sendo publicados em formato aberto no Portal de Libras e podem ser utilizados gratuitamente em diferentes contextos por toda a comunidade interessada. Além disso, o Portal também apresenta ferramentas que fomentem uma rede de formação e/ou Comunidade de Prática, viabilizando a interação em Libras e em Português. Foram desenvolvidas ferramentas que favoreçam a acessibilidade, indexação de informações, registro e upload de vídeos, constituindo-se numa possibilidade de pesquisas e desenvolvimento de produtos que poderão ser revertidos a toda comunidade surda e ouvinte.

Todos os materiais disponibilizados no Portal de Libras podem ser utilizados para formação em diferentes instâncias, por entidades públicas e privadas para fins educacionais relacionados com a Libras, a educação de surdos, a capacitação de profissionais, a formação de professores, tradutores e intérpretes. 


\section{DA ORGANIZAÇÃO E DISPONIBILIZAÇÃO DOS DADOS ON-LINE}

Com o objetivo de manter a segurança, por um lado, e por outro o acesso facilitado, todos os dados coletados são armazenados em servidor específico do Corpus de Libras, alocado no Núcleo de Processamento de Dados da UFSC.

Os dados do Corpus de Libras são organizados levando-se em conta a seguinte estrutura hierárquica: cidade, data da coleta, nome dos participantes. Na pasta, foram armazenados os dados "dados_editados", onde serão incluídos os arquivos já editados e configurados para a sua utilização no ELAN. Ambas as pastas foram subdivididas em: “_informante_1” e“_informante_2”, dentro das quais serão especificados: "tipo de dado" (i.e. entrevista, narrativa, eliciação, conversação); e, quando for o caso, o "_texto específico" (exemplo: Pear Story, no caso de narrativas; classificadores na sessão de eliciação). Os arquivos transcritos foram armazenados nas mesmas pastas em que estiverem localizados os arquivos de mídia editados que lhes servirão de base para transcrição.

A Antologia de Literatura em Libras envolveu a disponibilização de ferramentas de buscas em Libras e em português com espaço para postagem de outras antologias. A interface foi desenvolvida, pois não havia ainda nenhuma interface disponível. A disponibilização dos dados da Antologia foi feita por meio de uma interface acessível e amigável que foi desenvolvida com a participação de professores, tradutores, intérpretes de Libras.

O Quadro de Referência da Libras foi também disponibilizado por meio de uma interface em Libras e português com espaço para postagem de propostas de ensino de Libras entre os seus usuários. A interface conta com ferramentas de buscas eficientes que localizem temas de discussão e favoreçam as práticas pedagógicas. Este espaço tem como público-alvo principal os professores de Libras que atuam em diferentes níveis da educação, em especial, na educação básica.

A fim de viabilizar não apenas o armazenamento de dados e metadados do projeto num banco de dados consistente, mas também a disponibilização da documentação de forma on-line e gratuita para consulta por parte do público acadêmico, o banco de dados criado foi elaborado em consonância com a página on-line do Corpus de Libras, da antologia e do ensino de Libras, o que exigiu o diálogo entre os programadores das páginas, a congruência das mesmas no Portal de Libras e a equipe executiva do projeto.

\section{CONSIDERAÇÕES FINAIS}

O desenvolvimento do portal de Libras teve como objetivo apoiar a disseminação de conteúdos relacionados à Libras e à educação de surdos promovendo a formação de comunidades de prática. Neste sentido, a comunidade de prática refere-se à identidade partilhada em torno dos temas e desafios abordados no contexto do portal de Libras.

A complexidade da relação entre as informações, a quantidade e variedade do conteúdo disponível, a perspectiva de crescimento em função da demanda por materiais relacionados com a Libras, além da necessidade de valorização do visual e da Libras, exigiu o desenvolvimento de diferentes pesquisas teóricas sobre acessibilidade e surdez tendo em vista a escolha de tecnologias a serem utilizadas, bem como a elaboração de recursos tecnológicos inovadores.

O projeto envolveu estudos para a elaboração de uma arquitetura de informações que tornasse clara a organização dos conteúdos, permitindo que fossem localizados por uma orientação visual e pela língua de sinais,

Buscando uma solução para a navegação que permitisse localizar os materiais em no máximo dois níveis de profundidade, o menu principal foi organizado em cinco tópicos e subtópicos: Materiais (literários, acadêmicos e didáticos), Cursos (Libras, técnico, graduação, pós-graduação e outros), Língua (gramática, Signbank, glossários, ensino, Corpus de Libras e antologias), Pesquisas (projetos, grupos e dados estatísticos) e Espaço interativo. Os subtópicos direcionam para páginas com os conteúdos principais, como a gramática e banco de sinais ou para listas de opções como em materiais, cursos, glossários. 
Levando em consideração os estudos feitos, foram utilizados filtros que permitem aos usuários visualizarem, por exemplo, os materiais pelas miniaturas das capas ou pelas fotos dos autores e os cursos pela marca da instituição. Os tópicos oferecem filtros específicos permitindo ao usuário escolher visualizar apenas materiais em Libras ou português, público infantil, juvenil ou adulto, selecionar região e espaço de tempo, etc.

Os botões, em consonância com as orientações identificadas na literatura científica, possuem ícones, texto em português e texto em Libras apresentando as opções do menu, de modo a explorar a visualidade dos surdos e eliminar as ambiguidades na interpretação dos textos em português.

O sistema de buscas foi integrado com o banco de sinais (Libras Signbank) permitindo que o usuário selecione um sinal de forma facilitada e o sistema retorna uma palavra utilizada automaticamente para localizar no portal os assuntos relacionados.

O design de interação foi desenvolvido levando em consideração os estudos relacionados com a acessibilidade aos surdos considerando aspectos como navegabilidade e geração de valor em comunidades de prática e para promover maior engajamento do público do portal. Também foram feitos estudos de design editorial, com foco nos textos em Libras, visando promover uma leitura fluida e agradável. Para tanto foi adaptado um player de vídeo específico para a leitura em Libras.

O portal de Libras pretende reunir grande quantidade de dados e a organização visual desses dados pode ser muito útil e significativa. A partir dos conteúdos publicados, dados dos usuários e autores, e informações dos acessos, foram elaborados gráficos dinâmicos que indicam, por exemplo, tipos de cursos e materiais disponíveis e buscados, por regiões e por períodos. Tais informações podem subsidiar pesquisas e políticas públicas além de indicar possíveis melhorias no portal de Libras para desenvolvimentos futuros.

O projeto, com foco na experiência do usuário, visou a facilitar a catalogação, a navegação e as buscas com orientações visuais e bilíngues, e envolveu participantes surdos e ouvintes nas definições e nos testes de usabilidade.

\section{AGRADECIMENTOS}

Este trabalho foi possível pelos recursos do Conselho Nacional de Desenvolvimento Científico e Tecnológico - CNPQ (\# 440337/2017-8).

\section{REFERÊNCIAS}

AMBROSE, G.; HARRIS, P. Tipografia. Trad. de Priscila Lena Farias. Porto Alegre: Bookman, 2011.

CASTRO, N. P. A tradução de fábulas seguindo aspectos imagéticos da linguagem cinematográfica e da língua de sinais. 2012.165 f. Dissertação (Mestrado) - Programa de Pós-Graduação em Estudos da Tradução, Universidade Federal de Santa Catarina, Florianópolis, 2012.

COETZEe, L.; OLIVRIN, G.; VIVIERS, I. Accessibility Perspectives on Enabling South African Sign Language in the South African National Accessibility Portal. In: INTERNATIONAL WORLD WIDE WEB CONFERENCE W4A200, 18, Madrid, 2009. Proceedings... Madrid, Spain, 2009. p. 62-65.

FAJARDO, I. ; PARRA, E.; CAÑAS, J. J. Do sign language videos improve web navigation for deaf signer users? Journal of Deaf Studies and DeafEducation, v. 15, n. 3, p. 242-262, 2010. 
FAJARDO, I.; VIGO, M.; SALMERÓN, L. Technology for supporting web information search and learning in Sign Language. Interacting with Computers, v. 21, n. 4, p. 243-256, ago. 2009.

FOTINEA, S.-E.; EFTHIMIOU, E. Tools for deaf accessibility to an eGOV environment. Lecture Notes in Computer Science, n. 5105, 2008. p. 456-453.

FLOR, C. da S. Recomendações para a criação de pistas proximais de navegação em websites voltadas para surdos pré-linguísticos. 2016. 336 f. Tese (Doutorado) - Programa de Pós-graduação em Engenharia e Gestão do Conhecimento, Universidade Federal de Santa Catarina, Florianópolis, 2016.

GRANT, W. UX design: guia definitivo com as melhores práticas de UX. São Paulo: Novatec, 2019.

HICKS, J. The icon handbook. United Kingdom: Five Simple Steps, 2011.

KALBACH, J. Design de navegação web: Otimizando a Experiência do usuário. Porto Alegre: Bookman Editora, 2009.

LIBRAS. Portal de Libras. Disponível em: https://portal.libras.ufsc.br. Acesso em: 25 jan. 2021.

LIBRAS. Portal de Libras. 2020. Disponível em: https://libras.ufsc.br/. Acesso em: 25 abr. 2020.

LI, Y.; XU, J. C. Through virtual learning community to achieve liberated learning for deaf students. In: INTERNATIONAL CONFERENCE ON COMPUTER SCIENCE AND INFORMATION TECHNOLOGY, 2, Ukraine, 2009. Proceedings... Ukraine, 2009. p. 37-42.

LUPTON, E.; MILLER, A. Design, escrita, pesquisa: a escrita no design gráfico. Trad. Mariana Bandarra. Porto Alegre: Bookman. 2011.

NASR, M. M. An enhaced learning environment for Deaf/HOH pupils. In: 2nd International Conference on Computer Technology and Development. Cairo, Egypt, 2010. p. 724-727.

PREECE, J.; ROGERS, Y.; SHARP, H. Design de interação. Trad. Isabela Gasparini. 3. ed., São Paulo: Bookman, 2013.

ROSENFELD, L.; MORVILLE, P.; ARANGO, J. Information architecture: for the web and beyond. 4. ed., [s.l.]: O'Reilly Media, 2015.

SANTAELLA, L. A ecologia pluralista da comunicação: conectividade, mobilidade, ubiquidade. São Paulo: Paulus, 2010.

SILVA, R. C. da. Indicadores de formalidade no gênero monológico em libras. 2013. 161 f. Dissertação (Mestrado) - Programa de Pós-graduação em Linguística. Universidade Federal de Santa Catarina, Florianópolis, 2013.

TRINDADE, D. de F. G.; GUIMARÃES, C.; GARCÍA, L. S. conceptual framework of collaborative environments: cultivating communities of practice for deaf inclusion. In: INTERNATIONAL CONFERENCE ON ENTERPRISE INFORMATION SYSTEMS, 15. , Angers, 2013. Proceedings...Angers, 2013. p. 206-2015. 
WOLL, B. et. al. Signing books: testing of prototypes [1999]. Disponível em: http://www.sign-lang.unihamburg.de/signingbooks/sbrc/pdf/del 61.pdf. Acesso em: 10 jul. 2020.

\section{(c) (1) $\circledast \Theta$}

Recebido em 27/09/2020. Aceito em 25/10/2020. 